\title{
Solifenacin/tamsulosin fixed-dose combination therapy to treat lower urinary tract symptoms in patients with benign prostatic hyperplasia
}

This article was published in the following Dove Press journal:

Drug Design, Development and Therapy

19 March 2015

Number of times this article has been viewed

\author{
Konstantinos Dimitropoulos \\ Stavros Gravas \\ Department of Urology, Faculty \\ of Medicine, School of Health \\ Sciences, University of Thessaly, \\ Larissa, Greece
}

\begin{abstract}
Treatment of male lower urinary tract symptoms (LUTS) has traditionally focused on the management of benign prostatic obstruction, but the contribution of bladder dysfunction has been recently recognized. Therefore, it is well understood that LUTS have multifactorial etiology and often occur in clusters and not in isolation. Voiding LUTS are highly prevalent in men, but storage LUTS have been proved to be more bothersome. $\alpha_{1}$-Blockers are the most widely used pharmacologic agents for the treatment of symptoms relating to benign prostatic enlargement due to benign prostatic hyperplasia (BPH), while antimuscarinics are the drug class of choice for overactive bladder symptoms. A combination of the two drug classes would be a reasonable approach to treat men with both storage and voiding symptoms, and several shortterm studies have proved the efficacy and safety of different combinations with an $\alpha_{1}$-blocker and an antimuscarinic. Following previous studies on the separate administration of solifenacin and tamsulosin, a fixed-dose combination tablet of tamsulosin oral controlled absorption system (OCAS) $0.4 \mathrm{mg}$ and solifenacin succinate $6 \mathrm{mg}$ has been recently introduced, and the current review evaluates the available data on the use of this fixed-dose combination in the treatment of LUTS in men with BPH.
\end{abstract}

Keywords: benign prostatic obstruction, lower urinary tract symptoms, overactive bladder, fixed-dose combination, benign prostatic hyperplasia, tamsulosin, solifenacin

\section{Introduction}

Lower urinary tract symptoms (LUTS) are common in men over 45 years of age, ${ }^{1}$ and are divided into storage (urinary daytime frequency, nocturia, urinary urgency, incontinence), voiding (urinary hesitancy, slow stream, straining, splitting or spraying, intermittent stream, terminal dribbling), and postmicturition (feeling of incomplete emptying, postmicturition dribbling) symptoms. ${ }^{1,2}$ It has been found that $71 \%$ of male patients report symptoms from at least one LUTS group, and one-third of men all three groups. ${ }^{3}$ A large epidemiological study conducted in five countries revealed that approximately two-thirds of men report at least one LUTS complaint. ${ }^{4}$ Storage group symptoms are commonly linked with overactive bladder (OAB), based on the current definitions of International Incontinence Society. ${ }^{1}$

In men, LUTS have been historically attributed to bladder outlet obstruction (BOO) as a result of benign prostatic obstruction (BPO), which is often associated with benign prostatic enlargement $(\mathrm{BPE})$ resulting from the histologic condition of benign prostatic hyperplasia (BPH). ${ }^{1,5,6}$ Similar to LUTS, BPE is age-related; only $18 \%$ of 40 -year-old men suffer from prostatic enlargement, while $50 \%$ of 50 -year-old men and $90 \%$ of men in their 90 s report symptoms related to $\mathrm{BPE} / \mathrm{BPH} .^{7}$ As a result, pharmacological and surgical interventions mainly aimed to control BPE/BPO. However, it has to be noted
Correspondence: Stavros Gravas Medicine, School of Health Sciences, University of Thessaly, Feidiou 6-8, Larissa 4I22I, Greece

Tel +306944626086

Email sgravas2002@yahoo.com 
that $\mathrm{BPH} / \mathrm{BOO}$ is not the only cause of LUTS, as several other conditions have been proved to participate in LUTS pathogenetic pathways. OAB has also been typically believed to be more prevalent in women, but population-based prevalence studies showed that OAB symptoms affect up to $17 \%$ of the population, with age-related increases in both men and women. ${ }^{8}$ While voiding symptoms are the most prevalent ones in men, storage LUTS have been proved to cause a greater impact on the quality of life and embarrass and bother patients the most. ${ }^{9}$ The main players in the arena of medical treatment of male LUTS related to prostatic enlargement are $\alpha_{1}$-blockers and 5-alpha reductase inhibitors (5aRIs) either as monotherapy or as combination. However, the storage component of LUTS is commonly undertreated, as these widely used agents for voiding symptoms may fail to control OAB-like symptoms, ${ }^{6,10}$ and antimuscarinics are infrequently prescribed in men with BPE/BOO due to a widely prevalent, yet unproved, fear of post-void residual (PVR) increase, or, worse, acute urinary retention (AUR). ${ }^{11-16}$

Since a significant number of BPE/BPH patients suffer from both voiding and storage symptoms, a combination of drugs aiming at prostate and bladder would be a reasonable approach to control or alleviate symptoms. This was the rationale of several studies that evaluated the combined use of various $\alpha_{1}$-blockers and muscarinic receptor antagonists as initial or add-on treatment in men with OAB and BPE/BPO. The reported results led the European Association of Urology to add a treatment guideline that combination treatment with $\alpha_{1}$-blocker and antimuscarinic may be used in patients with bothersome moderate-to-severe nonneurogenic LUTS, if storage symptoms relief has been insufficient with monotherapy with either drug. Even though PVR increase was found to be clinically insignificant and risk for AUR was low, combination treatment is recommended with caution in men with possible BOO. ${ }^{2}$

A fixed-dose combination (FDC) tablet of tamsulosin oral controlled absorption system (OCAS) $0.4 \mathrm{mg}$ and solifenacin succinate 6 mg (Vesomni ${ }^{\mathrm{TM}}$, Astellas Pharma Europe BV, Leiden, the Netherlands) has been recently authorized for use in men with moderate-to-severe storage symptoms and voiding symptoms associated with BPH, not adequately responding to treatment with monotherapy. This study aims to review the literature about the use of tamsulosin/solifenacin FDC in controlling voiding and storage LUTS in men with BPE due to BPH.

A structured search was performed using articles in English language published in PubMed/Medline and Cochrane databases between 2000 and October 1, 2014, including the search terms "lower urinary tract symptoms", "benign prostatic hyperplasia", "solifenacin", "tamsulosin", and "fixed dose combination". Articles were systematically retrieved, selected, assessed, and summarized for this review.

\section{Overview of tamsulosin}

Noradrenaline-mediated contraction of prostate smooth muscles has been proposed to be implicated in the pathogenesis of $\mathrm{BOO}$ as a result of BPE/BPH. ${ }^{17}$ Moreover, it has been proved that human prostate smooth muscles contraction is driven almost exclusively by $\alpha_{1}$-adrenoceptors. ${ }^{18}$ As a result, $\alpha_{1}$-blockers have been long used to alleviate $\mathrm{BPH}$ related LUTS (BPH-LUTS) by blocking prostatic smooth muscle contraction and reducing induced BOO. However, urodynamic findings in men treated with $\alpha_{1}$-adrenergic antagonists for BPH-LUTS have shown that despite symptoms improvement, bladder obstruction was insignificantly altered by $\alpha_{1}$-blockers' action. ${ }^{19,20}$ Thus, other mechanisms of action may be relevant, such as mediation of chronic ischemia-induced LUTS by improving blood perfusion in prostate and bladder neck..$^{21,22}$

Tamsulosin has been proven to show selectivity for $\alpha_{1} \mathrm{~A}-$ and $\alpha_{1} \mathrm{D}$-adrenoceptors of prostate and bladder neck, ${ }^{23,24}$ and good affinity for $\alpha_{1}$ L-variant of $\alpha_{1}$ A-receptors. ${ }^{17}$

Bioavailability of tamsulosin reaches $90 \%$, and when administered, it occupies almost $80 \%$ of prostate $\alpha_{1}$ adrenoceptors within 4 hours, and remains bound to $44 \%$ of receptors at 24 hours postadministration. ${ }^{24}$ Its peak plasma concentration after administration $\left(C_{\max }\right)$ is $11.3 \mathrm{ng} / \mathrm{mL}$, with a median time to $C_{\max }\left(t_{\max }\right)$ of 6 hours; mean elimination half-life $\left(t_{1 / 2}\right)$ is 13.5 hours, while mean area under the serum concentration-time curve after single dose (AUC) is $187.2 \mathrm{ng} \cdot \mathrm{h} / \mathrm{mL} .^{24}$ In addition, tamsulosin can be safely used in patients with mild-to-moderate renal or hepatic impairment. ${ }^{25,26}$

The most frequently reported complications related to $\alpha_{1}$-blockers use comprise asthenia, dizziness, and orthostatic hypotension. ${ }^{2}$ Tamsulosin has been proved to have a very good cardiovascular tolerability. ${ }^{27}$ This was originally attributed to its $\alpha_{1} \mathrm{~A}$-adrenoceptors selectivity, therefore avoiding cardiovascular side effects related to the blockade of all three types of $\alpha_{1}$-receptors and especially $a_{1} B$ ones which have an increased role in the blood vessels of the elderly. ${ }^{28,29}$ However, this was not fully confirmed by studies findings. ${ }^{17}$ In addition, the OCAS tamsulosin formulation was independent of fed and fasted states and exhibited a somewhat longer $t_{\max }$ and markedly lower $C_{\text {max }}$ in single-dose studies and a lower ratio between the peak and 24-hour concentrations, resulting in a much safer cardiovascular profile. Tamsulosin reaches 
significantly higher concentrations in prostate rather than in plasma, further reducing its vascular side effects. . $^{30,31}$

Ejaculatory disorders represent another category of tamsulosin side effects. Originally, it was proposed that tamsulosin induced retrograde ejaculation by significantly reducing bladder obstruction. However, studies have shown that it is a form of anejaculation, ${ }^{32,33}$ possibly mediated by $\alpha_{1} \mathrm{~A}$ blockade. ${ }^{32}$ Intraoperative floppy iris syndrome is a complication of cataract surgery linked with $\alpha_{1}$-blockers treatment, mainly tamsulosin; $;^{34}$ however, the exact pathogenetic mechanism has not been clarified.

\section{Overview of solifenacin}

Acetylcholine resembles the neurotransmitter that mainly mediates human bladder contraction. It acts on all five subtypes of G-proteins-coupled muscarinic receptors, with M2 and M3 receptors being the most frequently detected ones in urothelium, interstitial and nerve cells, and detrusor smooth muscle..$^{35}$ In healthy bladder, M3 receptors are the most important ones for detrusor contraction, while M2 receptors activation seems to further enhance the contractile response mediated by M3 receptors. ${ }^{36,37}$ Moreover, M3 receptors have been found to regulate neurotransmitter release in presynaptic nerve terminals, while the presence of both $\mathrm{M} 2$ and $\mathrm{M} 3$ receptors in urothelium/ suburothelium has been proposed to be implicated in various clinical bladder syndrome pathogeneses. ${ }^{35}$

Thus, antimuscarinics use aims to reduce spontaneous detrusor activity in storage phase by the combined decrease of contractions frequency and intensity. ${ }^{35,38}$ In addition, it has been found that antimuscarinics also increase bladder capacity by inhibiting bladder afferent mechanisms during filling. ${ }^{39}$

Succinate salt of solifenacin is a relatively new antimuscarinic agent. Solifenacin binds to all types of muscarinic receptors and reaches peak concentration 3-8 hours after per os administration. ${ }^{40,41}$ Similar to tamsulosin, solifenacin has high bioavailability that reaches $90 \%$, independently of fasting state or not. Steady-state $C_{\max }$ for solifenacin 5 and $10 \mathrm{mg}$ is 32.3 and $62.9 \mathrm{ng} / \mathrm{mL}$, respectively, with a $t_{\max }$ ranging within 3-8 hours. Mean $t_{1 / 2}$ and AUC for 5 and $10 \mathrm{mg}$ doses are 64.4 and 60.9 hours, and 637 and 1,236 ng.h/mL, respectively. ${ }^{42}$ About $2-4$ weeks of once-daily administration are required to obtain full clinical effect. Solifenacin should be carefully used in patients with severe renal and moderate hepatic impairment or receiving CYP3A4 inhibitors, such as ketoconazole.

Compared to other antimuscarinics, solifenacin seems to be the more bladder-specific one, thus reducing other specific-organ-related side effects. ${ }^{35,40}$ Although solifenacin has been proved to have higher affinity for M 3 over M2 receptors and lower affinity for M1 and M5 receptors than the vast majority of antimuscarinics, this does not fully explain its bladder specificity, therefore necessitating further research. ${ }^{35,40}$ As with other antimuscarinic agents in use, the more frequent adverse events of solifenacin comprise dry mouth (due to M3 receptor antagonism in salivary glands), constipation (as M3 receptors mainly mediate bowel contraction), and blurred vision (since M3 receptors are found in human ciliary cells and iris sphincter muscles). ${ }^{35}$ Adverse events frequency seems to be dose-related for solifenacin, with $5 \mathrm{mg}$ being the safest dose. Risk for cardiac events, such as increased heart rate or QT interval prolongation is generally minimally affected when recommended doses are used.

As a tertiary amine, solifenacin can cross blood-brain barrier and bind to numerous M1 receptors located in neocortex, hippocampus, and neostriatum..$^{35,40}$ Expected central nervous system side effects comprise headache, somnolence, cognitive function impairment, and dizziness; however, an established causal relationship between solifenacin treatment and central nervous system adverse reactions has not been proved yet. ${ }^{35,40}$ Owing to their inhibitory effect on bladder detrusor contraction, antimuscarinics have been proven to increase PVR, although research has shown that induced increase is minimal, especially in men without BOO. Studies using monotherapy with tolterodine as an antimuscarinic agent in men with BOO, as well as studies using a combination of antimuscarinics, including solifenacin, with $\alpha_{1}$-blockers have shown minimal AUR risk in BOO patients with OAB symptoms. ${ }^{35,43}$ Nevertheless, administration of solifenacin in men with BOO seems to be safe; however, it should be performed with caution, with regular patients' follow-up and PVR reevaluation.

\section{Overview of studies on tamsulosin plus solifenacin combinations}

Several studies have evaluated the efficacy and safety of combined tamsulosin and solifenacin for the management of storage and voiding LUTS in men with BPE/BPH. Table 1 presents the design, primary and secondary end points, measured parameters, and final results of these studies. The reported therapeutic effects of tamsulosin and solifenacin in these studies were, to a certain degree, indicative of the action offered by FDC tablets and triggered the development of FDC. It should be underlined that these studies were characterized by a short follow-up, while patients enrolled had low baseline PVR. 


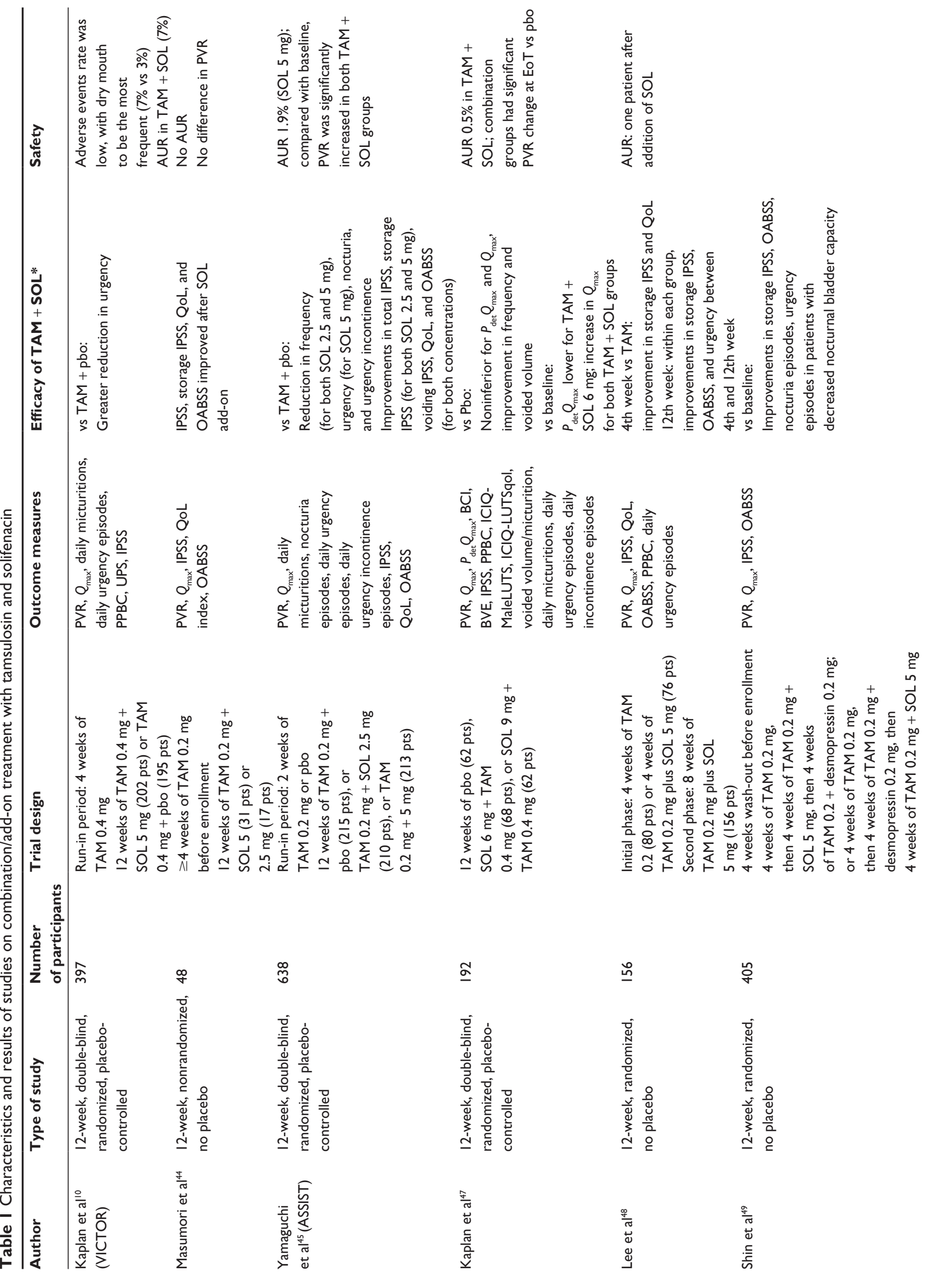



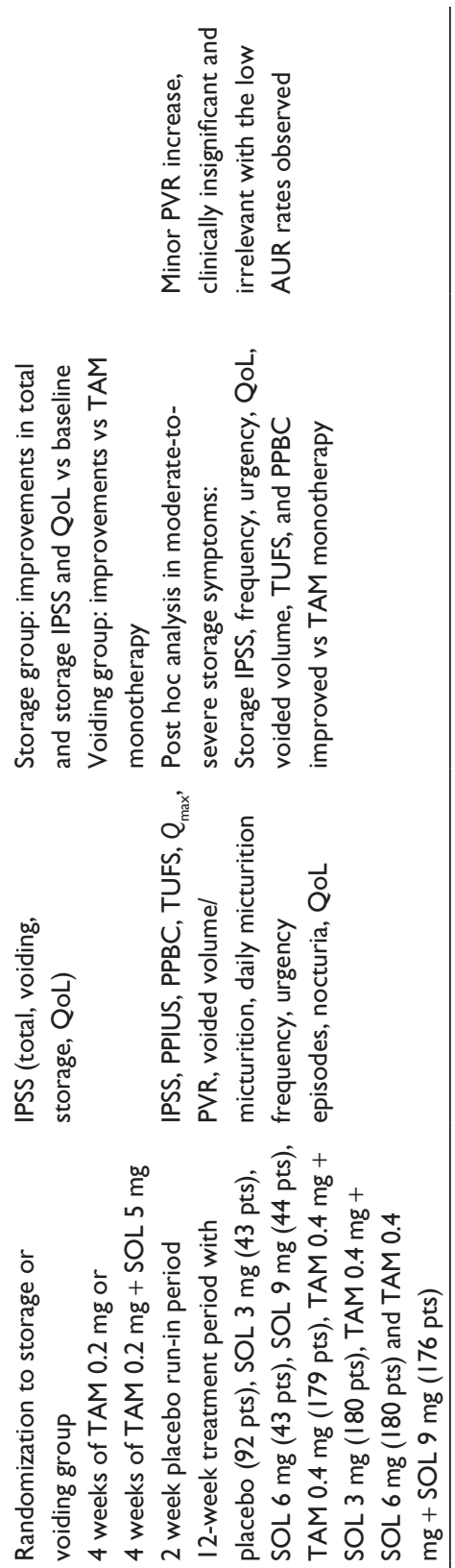

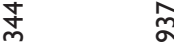
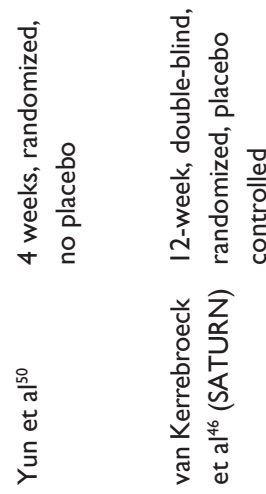

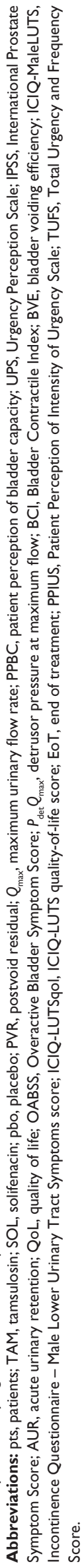

The VICTOR trial evaluated the safety and tolerability of adding solifenacin in men with residual OAB symptoms after monotherapy with tamsulosin. ${ }^{10}$ Solifenacin add-on led to significantly less urgency episodes than did placebo plus tamsulosin, with adverse events being rare, including low incidence of AUR.

Masumori et $\mathrm{al}^{44}$ studied the add-on effect of solifenacin (either 5 or $2.5 \mathrm{mg}$ ) for men with BPO and residual OAB symptoms after monotherapy with tamsulosin. They found that storage LUTS and quality of life (QoL) were significantly improved after solifenacin add-on. No difference was found between used solifenacin doses in terms of efficacy, and no AUR episodes or other serious adverse events were recorded. Constipation was the most frequent adverse event (5.3\%).

ASSIST was a large randomized controlled trial (RCT) from Japan assessing the efficacy and safety of solifenacin add-on therapy in men with BPH-related LUTS and residual storage symptoms despite initial tamsulosin administration. ${ }^{45}$ Patients were randomized to three treatment groups: tamsulosin plus placebo, tamsulosin plus solifenacin $2.5 \mathrm{mg}$, and tamsulosin plus solifenacin $5 \mathrm{mg}$. Urgency episodes were reduced in both combination treatment groups compared to tamsulosin plus placebo group, but only the $5 \mathrm{mg}$ solifenacin dose reached statistical significance. Patients in both combination groups experienced a significant decrease in daily micturitions and storage LUTS, compared with those seen in tamsulosin plus placebo group. PVR was significantly increased, but it was clinically insignificant in both combination groups, and the recorded AUR rate was low (1.9\%).

SATURN was a Phase 2 RCT on the efficacy and safety of various solifenacin doses combined with tamsulosin OCAS in men reporting LUTS. ${ }^{46}$ Solifenacin doses of 3, 6, and $9 \mathrm{mg}$ were used, and as a result patients were randomized into eight different subgroups. Solifenacin/tamsulosin combinations improved micturition frequency and voided volume per micturition, even though the International Prostate Symptom Score (IPSS) benefit was not confirmed. All solifenacin/ tamsulosin combinations were found to be safe, with minimal adverse events (with dry mouth and constipation the most prevalent), including nonclinically significant PVR volume increase and low AUR rates. The most interesting finding of SATURN was that in the subgroup of men with moderateto-severe storage and voiding symptoms, the $0.4 / 6$ and $0.4 / 9 \mathrm{mg}$ combination therapies led to significant storage LUTS improvement compared to tamsulosin monotherapy.

Solifenacin doses of 6 and $9 \mathrm{mg}$ were selected by Kaplan et al ${ }^{47}$ to investigate the safety of solifenacin plus tamsulosin OCAS combination in men with LUTS and BOO. This randomized, double-blind, parallel-group, placebo-controlled 
study showed that tamsulosin/solifenacin combinations were noninferior to placebo for $Q_{\max }$ and $P_{\text {det }} Q_{\max }$, at the end of the trial. While PVR was significantly increased in both combination groups, AUR rate was low. Similarly, the majority of reported adverse events were graded as mild or moderate. At the end of treatment, secondary efficacy end points analysis showed that micturition frequency and voided micturition volumes were significantly improved in both solifenacin groups versus placebo group.

Efficacy and safety of tamsulosin plus solifenacin combination as initial treatment were evaluated in Korean men with $\mathrm{BPH}$ and OAB symptoms. ${ }^{48}$ According to the study protocol, patients received either tamsulosin $0.2 \mathrm{mg}$ monotherapy or tamsulosin $0.2 \mathrm{mg}$ plus solifenacin $5 \mathrm{mg}$. After 4 weeks, both groups received combination therapy. Results from the initial phase of the trial showed that patients receiving combination treatment experienced better improvement in storage symptoms and QoL, compared to patients treated with tamsulosin monotherapy. At end of the trial, no difference in storage indices was revealed between the two groups, and both groups experienced significant improvements in storage LUTS compared to baseline. Mild adverse events were observed and AUR rate was low after solifenacin addition. It was concluded that earlier combination treatment led to an early improvement in storage symptoms and QoL in men with BPH and OAB symptoms.

Shin et $\mathrm{al}^{49}$ conducted a trial that studied the efficacy and safety of an anticholinergic and an antidiuretic agent as add-on therapy for refractory nocturia in men with BPH treated with tamsulosin. Nocturnal voiding disorders were categorized as nocturnal polyuria, decreased nocturnal bladder capacity, or nocturia caused by both causes. The trial design is presented in Table 1. Subanalysis of study results showed that in both groups, solifenacin addition to tamsulosin therapy led to improvement in storage IPSS and frequency of nocturia and urgency episodes if decreased nocturnal bladder capacity was the main underlying cause.

Yun et $\mathrm{al}^{50}$ investigated whether men with LUTS can be treated initially with tamsulosin monotherapy or combined with solifenacin, based on patients' reported most bothersome symptom. Patients were categorized into storage $(60 \%$ of participants) and voiding (40\%) groups, based on the most bothersome symptoms among the IPSS items. In each group, patients were randomized to receive tamsulosin monotherapy or combination therapy of tamsulosin plus solifenacin. In terms of IPSS and QoL improvement, storage group benefited more from combination therapy, while voiding group benefited from monotherapy with tamsulosin.

All aforementioned studies evaluated a combination of tamsulosin and solifenacin as initial combination, or add-on therapy, for controlling LUTS in men with BPE/BPH. However, only two studies assessed the use of FDC tablet of solifenacin and tamsulosin in men with LUTS: the Phase III NEPTUNE and NEPTUNE II studies. ${ }^{13,14}$

The NEPTUNE trial was a double-blind Phase III study aiming to evaluate the safety and efficacy of 12-week treatment with two different tamsulosin and solifenacin FDCs in comparison with placebo and tamsulosin monotherapy in 1,334 men with combined moderate-or-severe voiding and storage LUTS. ${ }^{13}$ Combinations of tamsulosin/solifenacin used were $0.4 / 6$ or $0.4 / 9 \mathrm{mg}$. The two primary efficacy variables were the total IPSS and the Total Urgency and Frequency Score (TUFS). According to the study results, the $0.4 / 6 \mathrm{mg}$ FDC was superior to placebo and noninferior to tamsulosin monotherapy in reducing mean total IPSS score, and superior to tamsulosin in reducing mean TUFS. Compared with tamsulosin, both doses of FDCs led to significant improvements in the IPSS storage subscore, micturition frequency, mean voided volume per micturition, and QoL parameters, as a result of solifenacin properties (Table 2). It has to be noted that $0.4 / 9 \mathrm{mg}$ FDC was not found to offer additional benefits, compared with the effects of $0.4 / 6 \mathrm{mg}$ FDC, which is attributed (by the authors) to a possible plateau effect.

Overall, $30.1 \%$ of patients reported AEs during treatment with FDC. Most AEs were considered unrelated to the study medication by the investigators. Drug-related AEs were more frequent with FDCs than with placebo or tamsulosin OCAS (Table 2). The incidence of AUR requiring catheterization in NEPTUNE population was $0.3 \%$ in $0.4 / 6 \mathrm{mg}$ FDC, $0.9 \%$ in $0.4 / 9 \mathrm{mg}$ FDC, and $0.3 \%$ in tamsulosin monotherapy. At the same time, minor increases in PVR volume were observed in both FDC groups, judged, however, to be clinically insignificant and not associated with AUR rates. As a general conclusion, NEPTUNE showed that 12-week treatment with $0.4 / 6 \mathrm{mg}$ FDC offered benefits in patients with moderate or severe storage and voiding LUTS.

In order to evaluate the long-term safety and efficacy of tamsulosin plus solifenacin FDC, patients who completed the NEPTUNE trial were offered to continue into the 40-week NEPTUNE II study. ${ }^{14}$ NEPTUNE II was an open-label, flexible-dose, extension study. All patients started with $0.4 / 6 \mathrm{mg}$ FDC for 4 weeks, and then patients could opt to change to $0.4 / 9 \mathrm{mg}$ FDC or remain at $0.4 / 6 \mathrm{mg}$ FDC. According to the study protocol, all patients could request the dose switch at any following visit, without restrictions. Total IPSS score was reduced by 9.0 points over the trial duration, indicating a significant and sustained improvement in symptoms reported by patients. A significant 10.1-point reduction in TUFS was also achieved with treatment of up to 52 weeks, 





confirming sustained improvements observed in both urinary urgency and frequency. Patient satisfaction and QoL were also improved, a finding mainly attributed to storage symptoms improvement. $Q_{\max }$, volume of micturitions, urgency, incontinence episodes, and voided volume per micturition were found to be improved at the end of treatment in comparison to baseline, while a small increase in PVR was revealed (Table 2). While almost half the patients $(46.8 \%)$ experienced treatment-emergent adverse events, most of them were mild or moderate in severity. Observed AUR rate in NEPTUNE II was $0.7 \%$, even though $50 \%$ of study participants were in high risk for AUR due to prostate enlargement at baseline estimation. Of those ending the study on $0.4 / 6 \mathrm{mg}$ FDC, $87.7 \%$ were satisfied with its safety and $87.0 \%$ were satisfied with its efficacy, versus $85.8 \%$ and $73.3 \%$, respectively, for those ending the study on $0.4 / 9 \mathrm{mg}$ FDC. When asked which dose they would have taken had the study continued, 681 (70.2\%) indicated $0.4 / 6$ $\mathrm{mg}$ FDC and 289 (29.8\%) indicated $0.4 / 9 \mathrm{mg}$ FDC. The majority of patients $(70.2 \%$ ) would have selected $0.4 / 6 \mathrm{mg}$ FDC as the preferred treatment if the study had continued, because no additional benefit was found with the $0.4 / 9 \mathrm{mg}$ FDC, whereas fewer patients were satisfied with its safety.

Therefore, NEPTUNE II provided evidence on the safety and efficacy of $0.4 / 6 \mathrm{mg}$ FDC in the management of moderate-to-severe LUTS in men with BPE/BPH. The main characteristics and outcomes of studies using the FDC are presented in Table 2.

A wide heterogeneity is observed in the available studies on tamsulosin plus solifenacin in terms of the studied populations, the outcome measures, the doses of tamsulosin or solifenacin used, the duration and design of therapeutic protocol, and the external validity of obtained results. The vast majority of studies are of short duration, in contrast with the long-term medical treatment required in real clinical practice. Therefore, issues of patient adherence to therapy and long-term safety and efficacy of the combination treatment are raised. Studies conducted in Asian populations used tamsulosin $0.2 \mathrm{mg}$ in contrast to the commonly used dose of 0.4 $\mathrm{mg},{ }^{44,45,48-50}$ while large discrepancies are also revealed in the dose of solifenacin used, as doses of 3, 5, 6, and $9 \mathrm{mg}$ were used and compared in different studies. ${ }^{10,13,14,44-50}$ Finally, the noninferiority design selected in some of the major studies dictates the need to evaluate the findings with caution.

Patients' nonadherence to medical treatment of male LUTS represents a significant problem. ${ }^{51}$ It has been found that combination therapies result in better compliance compared to monotherapies. ${ }^{51,52}$ In addition, it has been shown that less frequent dosage enhances adherence, and technical adherence interventions are usually directed at simplifying the medication regimen..$^{53}$ Therefore, a potential advantage of the FDC of solifenacin/tamsulosin may be the improvement of patients' adherence.

\section{Conclusion}

Current guidelines suggest the use of combination treatment ( $\alpha_{1}$-blocker and antimuscarinic) in patients with bothersome LUTS, if storage symptoms relief has been insufficient with monotherapy with either drug. ${ }^{2}$ Efforts have been made to develop algorithms in order to assist clinicians to select those patients who will benefit more from the combination therapy. ${ }^{2,54}$ In accordance with previous studies on the separate administration of solifenacin and tamsulosin, data on the tamsulosin OCAS $0.4 \mathrm{mg}$ with solifenacin $6 \mathrm{mg}$ FDC showed that FDC results in significant amelioration of storage symptoms and improvement in overall QoL in men with storage and voiding LUTS, compared to tamsulosin monotherapy. FDC was well tolerated without significantly increasing the risk of AUR despite an increase in PVR.

Yet more large-scale studies on tamsulosin/solifenacin FDC for the management of storage and voiding LUTS in men with BPH are required, as long-term follow-up data are lacking, and methodological discrepancies exist in the available studies. In addition, issues of optimal patient selection, patients' adherence, and cost of treatment also need to be investigated.

\section{Disclosure}

The authors report no conflicts of interest in this work.

\section{References}

1. Abrams P, Cardozo L, Fall M, et al. The standardisation of terminology in lower urinary tract function: report from the standardisation subcommittee of the International Continence Society. Urology. 2003;61(1): $37-49$.

2. Oelke M, Bachmann A, Descazeaud A, et al. EAU guidelines on the treatment and follow-up of non-neurogenic male lower urinary tract symptoms including benign prostatic obstruction. Eur Urol. 2013;64(1): $118-140$

3. Sexton CC, Coyne KS, Kopp ZS, et al. The overlap of storage, voiding and postmicturition symptoms and implications for treatment seeking in the USA, UK and Sweden: EpiLUTS. BJU Int. 2009;103(Suppl 3):12-23.

4. Irwin DE, Milsom I, Hunskaar S, et al. Population-based survey of urinary incontinence, overactive bladder, and other lower urinary tract symptoms in five countries: results of the EPIC study. Eur Urol. 2006;50(6):1306-1314; discussion 1314-1315.

5. Chapple CR, Wein AJ, Abrams P, et al. Lower urinary tract symptoms revisited: a broader clinical perspective. Eur Urol. 2008;54(3):563-569.

6. Chapple CR, Roehrborn CG. A shifted paradigm for the further understanding, evaluation, and treatment of lower urinary tract symptoms in men: focus on the bladder. Eur Urol. 2006;49(4):651-658.

7. Jacobsen SJ, Girman CJ, Lieber MM. Natural history of benign prostatic hyperplasia. Urology. 2001;58(6 Suppl 1):5-16; discussion 16. 
8. Kaplan SA, Roehrborn CG, Chapple CR, et al. Implications of recent epidemiology studies for the clinical management of lower urinary tract symptoms. BJU Int. 2009;(103 Suppl 3):48-57.

9. Peters TJ, Donovan JL, Kay HE, et al. The International Continence Society "Benign Prostatic Hyperplasia" Study: the botherosomeness of urinary symptoms. J Urol. 1997;157(3):885-889.

10. Kaplan SA, McCammon K, Fincher R, Fakhoury A, He W. Safety and tolerability of solifenacin add-on therapy to alpha-blocker treated men with residual urgency and frequency. J Urol. 2009;182(6): 2825-2830.

11. Abrams P, Kaplan S, De Koning Gans HJ, Millard R. Safety and tolerability of tolterodine for the treatment of overactive bladder in men with bladder outlet obstruction. J Urol. 2006;175(3 Pt 1):999-1004; discussion 1004

12. Kaplan SA, Wein AJ, Staskin DR, Roehrborn CG, Steers WD. Urinary retention and post-void residual urine in men: separating truth from tradition. J Urol. 2008;180(1):47-54.

13. Van Kerrebroeck P, Chapple C, Drogendijk T, et al. Combination therapy with solifenacin and tamsulosin oral controlled absorption system in a single tablet for lower urinary tract symptoms in men: efficacy and safety results from the randomised controlled NEPTUNE trial. Eur Urol. 2013;64(6):1003-1012.

14. Drake MJ, Chapple C, Sokol R, et al. Long-term safety and efficacy of single-tablet combinations of solifenacin and tamsulosin oral controlled absorption system in men with storage and voiding lower urinary tract symptoms: results from the NEPTUNE Study and NEPTUNE II open-label extension. Eur Urol. Epub July 25, 2014.

15. Morant SV, Reilly K, Bloomfield GA, Chapple C. Diagnosis and treatment of lower urinary tract symptoms suggestive of overactive bladder and bladder outlet obstruction among men in general practice in the UK. Int J Clin Pract. 2008;62(5):688-694.

16. Helfand BT, Evans RM, McVary KT. A comparison of the frequencies of medical therapies for overactive bladder in men and women analysis of more than 7.2 million aging patients. Eur Urol. 2010;57(4): 586-591.

17. Michel MC. The forefront for novel therapeutic agents based on the pathophysiology of lower urinary tract dysfunction: alpha-blockers in the treatment of male voiding dysfunction - how do they work and why do they differ in tolerability? J Pharmacol Sci. 2010;112(2): 151-157.

18. Michel MC, Vrydag W. Alpha1-, alpha2- and beta-adrenoceptors in the urinary bladder, urethra and prostate. Br JPharmacol. 2006;(147 Suppl 2): S88-S119.

19. Kortmann BB, Floratos DL, Kiemeney LA, Wijkstra H, de la Rosette JJ. Urodynamic effects of alpha-adrenoceptor blockers: a review of clinical trials. Urology. 2003;62(1):1-9.

20. Barendrecht MM, Abrams P, Schumacher H, de la Rosette JJ, Michel MC. Do alpha1-adrenoceptor antagonists improve lower urinary tract symptoms by reducing bladder outlet resistance? Neurourol Urodyn 2008;27(3):226-230.

21. Pinggera G-M, Mitterberger M, Steiner E, et al. Association of lower urinary tract symptoms and chronic ischaemia of the lower urinary tract in elderly women and men: assessment using colour Doppler ultrasonography. BJU Int. 2008;102(4):470-474.

22. Pinggera G-M, Mitterberger M, Pallwein L, et al. alpha-Blockers improve chronic ischaemia of the lower urinary tract in patients with lower urinary tract symptoms. BJU Int. 2008;101(3):319-324.

23. Michel MC, Grübbel B, Taguchi K, Verfürth F, Otto T, Kröpfl D. Drugs for treatment of benign prostatic hyperplasia: affinity comparison at cloned alpha1-adrenoceptor subtypes and in human prostate. J Auton Pharmacol. 1996;16(1):21-28.

24. Keating GM. Dutasteride/tamsulosin: in benign prostatic hyperplasia. Drugs Aging. 2012;29(5):405-419.

25. Wolzt M, Fabrizii V, Dorner GT, et al. Pharmacokinetics of tamsulosin in subjects with normal and varying degrees of impaired renal function: an open-label single-dose and multiple-dose study. Eur J Clin Pharmacol. 1998;54(4):367-373.
26. Miyazawa Y, Blum RA, Schentag JJ, et al. Pharmacokinetics and safety of tamsulosin in subjects with normal and impaired renal or hepatic function. Curr Ther Res. 2001;62(9):603-621.

27. Michel MC, Mehlburger L, Bressel HU, Schumacher H, Schäfers RF, Goepel M. Tamsulosin treatment of 19,365 patients with lower urinary tract symptoms: does co-morbidity alter tolerability? J Urol. 1998; 160(3 Pt 1):784-791.

28. Guimarães S, Moura D. Vascular adrenoceptors: an update. Pharmacol Rev. 2001;53(2):319-356.

29. Rudner XL, Berkowitz DE, Booth JV, et al. Subtype specific regulation of human vascular alpha(1)-adrenergic receptors by vessel bed and age. Circulation. 1999;100(23):2336-2343.

30. Martin C, Michel CK. Comparison of vascular $\alpha$ 1adrenoceptor antagonism of tamsulosin in oral controlled absorption system (OCAS) and modified release (MR) formulations. Eur Urol Suppl. 2005;4(2):45-52.

31. Michel MC, Korstanje C, Krauwinkel W, Shear M, Davies J, Quartel A. Cardiovascular safety of the oral controlled absorption system (OCAS) formulation of tamsulosin compared to the modified release (MR) formulation. Eur Urol Suppl. 2005;4(2):53-60.

32. Van Dijk MM, de la Rosette JJ, Michel MC. Effects of alpha(1)adrenoceptor antagonists on male sexual function. Drugs. 2006;66(3): 287-301.

33. Hisasue S, Furuya R, Itoh N, Kobayashi K, Furuya S, Tsukamoto T. Ejaculatory disorder caused by alpha-1 adrenoceptor antagonists is not retrograde ejaculation but a loss of seminal emission. Int J Urol. 2006;13(10):1311-1316.

34. Chang DF, Campbell JR. Intraoperative floppy iris syndrome associated with tamsulosin. J Cataract Refract Surg. 2005;31(4):664-673.

35. Abrams P, Andersson K-E. Muscarinic receptor antagonists for overactive bladder. BJU Int. 2007;100(5):987-1006.

36. Andersson K-E, Wein AJ. Pharmacology of the lower urinary tract: basis for current and future treatments of urinary incontinence. Pharmacol Rev. 2004;56(4):581-631.

37. Ehlert FJ, Griffin MT, Abe DM, et al. The M2 muscarinic receptor mediates contraction through indirect mechanisms in mouse urinary bladder. J Pharmacol Exp Ther. 2005;313(1):368-378.

38. Andersson KE. Storage and voiding symptoms: pathophysiologic aspects. Urology. 2003;62(5 Suppl 2):3-10

39. Andersson K-E. Antimuscarinics for treatment of overactive bladder. Lancet Neurol. 2004;3(1):46-53.

40. Doroshyenko O, Fuhr U. Clinical pharmacokinetics and pharmacodynamics of solifenacin. Clin Pharmacokinet. 2009;48(5):281-302.

41. Ohtake A, Saitoh C, Yuyama H, et al. Pharmacological characterization of a new antimuscarinic agent, solifenacin succinate, in comparison with other antimuscarinic agents. Biol Pharm Bull. 2007;30(1):54-58.

42. VESICARE ${ }^{\circledR}$ [product monograph]. Markham, ON: Astellas Pharma Canada, Inc; 2013. Available from: http://www.cmsastellas.ca/uploads/ pdf/2013-09-19\%20Vesicare-PM-Approved.pdf. Accessed November $1,2014$.

43. Kaplan SA, Walmsley K, Te AE. Tolterodine extended release attenuates lower urinary tract symptoms in men with benign prostatic hyperplasia. J Urol. 2005;174(6):2273-2275; discussion 2275-2276.

44. Masumori N, Tsukamoto T, Yanase M, Horita H, Aoki M. The add-on effect of solifenacin for patients with remaining overactive bladder after treatment with tamsulosin for lower urinary tract symptoms suggestive of benign prostatic obstruction. Adv Urol. 2010: 205251.

45. Yamaguchi O, Kakizaki H, Homma Y, et al. Solifenacin as add-on therapy for overactive bladder symptoms in men treated for lower urinary tract symptoms - ASSIST, randomized controlled study. Urology. 2011;78(1):126-133.

46. Van Kerrebroeck P, Haab F, Angulo JC, et al. Efficacy and safety of solifenacin plus tamsulosin OCAS in men with voiding and storage lower urinary tract symptoms: results from a phase 2, dose-finding study (SATURN). Eur Urol. 2013;64(3):398-407. 
47. Kaplan SA, He W, Koltun WD, Cummings J, Schneider T, Fakhoury A. Solifenacin plus tamsulosin combination treatment in men with lower urinary tract symptoms and bladder outlet obstruction: a randomized controlled trial. Eur Urol. 2013;63(1):158-165.

48. Lee SH, Byun SS, Lee SJ, Kim KH, Lee JY. Effects of initial combined tamsulosin and solifenacin therapy for overactive bladder and bladder outlet obstruction secondary to benign prostatic hyperplasia: a prospective, randomized, multicenter study. Int Urol Nephrol. 2014;46(3):523-529.

49. Shin YS, Zhang LT, Zhao C, Kim YG, Park JK. Twelve-week, prospective, open-label, randomized trial on the effects of an anticholinergic agent or antidiuretic agent as add-on therapy to an alpha-blocker for lower urinary tract symptoms. Clin Interv Aging. 2014;9:1021-1030.

50. Yun JH, Kim JH, Kim JH, et al. Can we decide the optimal initial treatment for male lower urinary tract symptoms patients with overactive bladder by the most bothersome symptom? A randomized, prospective, open-label study. Urol Int. 2014;93(3):338-343.
51. Nichol MB, Knight TK, Wu J, Barron R, Penson DF. Evaluating use patterns of and adherence to medications for benign prostatic hyperplasia. J Urol. 2009;181(5):2214-2221; discussion 2221-2222.

52. Lin Y-H, Jiang Y-G, Wang J-S, Luo Y. Finasteride adherence-associated factors in Chinese benign prostatic hyperplasia patients. Urol Int. 2012;88(2):177-182.

53. Van Dulmen S, Sluijs E, van Dijk L, de Ridder D, Heerdink R, Bensing J. Patient adherence to medical treatment: a review of reviews. $B M C$ Health Serv Res. 2007;7:55.

54. Gravas S, Melekos MD. Male lower urinary tract symptoms: how do symptoms guide our choice of treatment? Curr Opin Urol. 2009; 19(1):49-54.

\section{Publish your work in this journal}

Drug Design, Development and Therapy is an international, peerreviewed open-access journal that spans the spectrum of drug design and development through to clinical applications. Clinical outcomes, patient safety, and programs for the development and effective, safe, and sustained use of medicines are a feature of the journal, which has also been accepted for indexing on PubMed Central. The manuscript management system is completely online and includes a very quick and fair peer-review system, which is all easy to use. Visit http://www.dovepress.com/testimonials.php to read real quotes from published authors.

Submit your manuscript here: http://www.dovepress.com/drug-design-development-and-therapy-journal 